\title{
USOS DEL TERRITORIO, ACUMULACIÓN POR DESPOSESIÓN Y DERECHO A LA SALUD EN LA ARGENTINA CONTEMPORÁNEA: EL CASO DE LA SOJA TRANSGÉNICA
}

\author{
Sebastián Gómez Lende* \\ Universidad Nacional del Centro de la Provincia de Buenos Aires ${ }^{* *}$
}

Resumo: Emergente na aurora do sistema capitalista, a acumulação por espoliação é uma parte fundamental da ordem global. Como resultado, os usos modernos do território tornaram-se irracionais para grande parte da sociedade, exceto para os agentes hegemônicos. Esta irracionalidade é mais aguda e óbvia quando o avanço da fronteira de acumulação capitalista priva as pessoas do direito à saúde, ameaçando a reprodução da vida humana. Neste artigo, argumenta-se que a Argentina é atualmente o cenário de um conflito insolúvel e cada vez mais frequente entre o primado de determinado uso globalizado do território e a reprodução do direito à saúde das comunidades locais envolvidas. À luz desta premissa, o trabalho analisa o boom da soja transgênica e as suas graves implicações para a saúde pública. Conclui-se que o modelo sojeiro opera como uma forma de acumulação por espoliação em múltiplas dimensões da vida social, incluindo a esfera da saúde.

Palavras-chave: usos do território; acumulação por espoliação; saúde pública; soja GM; Argentina.

\section{USES OFTERRITORY, ACCUMULATION BY DISPOSSESSION AND RIGHT TO HEALTH IN CONTEMPORARY ARGENTINA: THE CASE OF TRANSGENIC SOYBEAN}

\begin{abstract}
Originating at the dawn of the capitalism, accumulation by dispossession is a key part of the global order. As a result, modern uses of territory have become irrational for most of society but the hegemonic agents. This irrationality becomes more acute and obvious when the advancing frontier of capitalist accumulation deprives people of the right to health and threates the reproduction of human life. In this paper, it is argued that Argentina is currently the scene of an insoluble and increasingly frequent conflict between the primacy of certain globalized uses of territory and the right to health of the local communities involved. In light of this hypothesis, the article analyses the boom of transgenic soybean and its serious implications for public health. It is concluded that this model operates as a form of accumulation by dispossession in multiple dimensions of social life, including health sphere.
\end{abstract}

Keywords: uses of territory; accumulation by dispossession; public health; transgenic soybean; Argentina. 
Originada en los albores del sistema capitalista, la acumulación por desposesión constituye una pieza clave del orden global. Como resultado, los usos modernos del territorio se han tornado irracionales para gran parte de la sociedad, a excepción de los agentes hegemónicos. Esta irracionalidad se vuelve más aguda y evidente cuando el avance de la frontera de la acumulación capitalista despoja a la población del derecho a la salud y atenta contra la reproducción de la vida humana. En este trabajo, se sostiene que la Argentina es, en la actualidad, escenario de una insoluble y cada vez más asidua contradicción entre la primacía de ciertos usos globalizados del territorio y la reproducción del derecho a la salud de las comunidades locales implicadas. A la luz de esa premisa, se efectúa un pormenorizado análisis del boom de la soja transgénica como estudio de caso, atendiendo a las graves implicancias socio-sanitarias de dicho modelo.

En primer término, se desarrolla una breve discusión teórica sobre los conceptos de espacio geográfico, usos del territorio y acumulación por desposesión, y sus vínculos respecto de la vulneración del derecho a la salud. A continuación, se presenta una escueta caracterización del estudio de caso elegido, esto es, el auge de la soja transgénica en la Argentina, y la función que, en términos generales, esta actividad desempeña en la acumulación por desposesión. El siguiente apartado analiza las consecuencias sanitarias del modelo sojero, efectuando especial énfasis en el impacto de las fumigaciones con agro-tóxicos sobre la salud de la población de distintas localidades de la pampa húmeda y el norte del país; dicho análisis se fundamenta en los hallazgos y correlaciones obtenidas por distintos relevamientos y estudios epidemiológicos. Finalmente, se presentarán las conclusiones a las que este trabajo ha arribado.

\section{Espacio geográfico, usos del territorio, acumulación por desposesión y derecho a la salud}

Santos (1996a, p.39) define al espacio geográfico como un conjunto solidario, indisociable y contradictorio de sistemas de objetos y sistemas de acciones mediados por normas. En ese sistema de ideas, el territorio es conceptualizado como el espacio explicado a partir de sus usos (Santos y Silveira, 2001, p. 20). Los usos del territorio desarrollados en países y lugares constituyen expresiones de la división internacional del trabajo, funcionalizaciones del orden global que, en el período actual, exhiben ciertos rasgos y atributos comunes - mundialización del capital, producción globalizada, actividades modernas, normas internacionales, etc -. Como resultado, surge el territorio de las verticalidades, reino de fuerzas organizacionales y externas que, al imponer cambios que satisfacen la lógica del mercado y los agentes dominantes, crean desorden en el ámbito local y hacen tabla rasa de la historia pretérita y sus herencias espaciales (Santos, 1996a p.109; 1996b, p.137; Silveira, 1999, p.401).

En la actualidad, buena parte de los usos modernos del territorio encarnan a formas o modalidades de lo que Harvey (2004, p.116) denomina 'acumulación por desposesión'. Este concepto remite a su vez al de 'acumulación primitiva' u 'originaria', es decir, al acto histórico de despojo violento que instauró las relaciones sociales capitalistas a escala mundial que fue crucial para la formación del stock de capital necesario para la Revolución Industrial europea. No obstante, la acumulación basada en la depredación, el fraude y la violencia no es un fenómeno propio de una etapa histórica ya superada; por el contrario, constituye un aspecto esencial del capitalismo presente en todas las épocas y países (Composto, 2012, p. 235). No obstante, este fenómeno se expresa con mayor crudeza en la periferia del sistema, donde el avance del despojo garantiza la reproducción ampliada del capital en el centro (Amin, 1975, p. 15).

Es imperativo, pues, estudiar las prácticas depredadoras del capitalismo, es decir, analizar los distintos mecanismos que jalan hacia la órbita del capital recursos y población hasta entonces ajenos a la lógica del sistema (Tetreault, 2013, p. 193). Esta invasión legal y factual de los 'patrimonios de uso común' y otros 'campos fronterizos a la matiz capitalista' (Garibay Orozco, 2010, p. 136-137 y 167) opera despojando a territorios y grupos sociales desus bienes comunesy derechos históricamente adquiridos (Bellisario, 2003, p.55), prácticas que son respaldadas y promovidas -aún en contra de la voluntad popular- por el propio Estado (Harvey, 2004, p.116 y 118).

La oleada contemporánea de acumulación por desposesión contempla antiguas y nuevas modalidades de despojo. Se observa el recrudecimiento, por un lado, de la mercantilización y privatización de la tierra, el desplazamiento degranjas familiaresyla expulsiónforzosa de comunidades campesinas y aborígenes, la conversión de la propiedad comunal o colectiva en propiedad privada, la apropiación colonial, neocolonial e imperial de recursos, la eliminación de formas de producción y consumo alternativas (indígenas y campesinas), la monetarización del intercambio, la expoliación financiera -vía crédito, usura y deuda nacional - y ciertas formas de esclavitud. Otros rasgos más actuales, desarrollados a partir de finales de la década de 1980, atañen a la privatización de empresas y servicios públicos, el desmantelamiento de los sistemas de regulación y protección laboral y ambiental, la privatización y sobreexplotación de 
recursos naturales -a través del retorno al extractivismo-, y la mercantilización y degradación del hábitat - tierra, agua, aire, etc (Harvey, 2004, p.116 - 118, 121 y 122 - 124; Composto, 2012, p. 331; Sacher, 2015, p. 105).

Otras formas de cercamiento, más novedosas y sofisticadas, conciernen a los derechos de propiedad intelectual. Las patentes y licencias de material genético y plasma de semillas, por ejemplo, han conducido a la legalización/legitimación de los mecanismos de apropiación privada de la naturaleza, en un intento por mercantilizar y subsumir todos los aspectos esenciales de la vida humana a los requerimientos de la acumulación capitalista (Perelmuter, 2011, p. 60-62). El resultado ha sido el crecimiento de la biopiratería y el pillaje de la reserva mundial de recursos genéticos en beneficio de las transnacionales biotecnológicas y farmacéuticas (Harvey, 2004, p. 118).

La acumulación por desposesión se desarrolla a partir de tres dinámicas expropiatorias: a) la expropiación geográfica, donde los espacios locales se convierten en enclaves exportadores subordinados a lógicas globales que desintegran su matriz productiva, eliminan su diversidad territorial y social, y destruyen su coherencia interna; b) la expropiación económica, basada en la transferencia de recursos financieros hacia los centros de poder mundial; y c) la expropiación ecológica, donde la división internacional del trabajo, el comercio exterior y la inversión extranjera directa operan combinadamente para generar la apropiación diferencial de bienes y servicios ambientales (Machado Araoz, 2010, p. 79-90). En todos los casos, el Estado legitima esos dispositivos so pretexto de modernidad, progreso e inserción en el mercado mundial. Surge así un patrón social, económico, político y territorial donde el orden de prioridades funcional a los actores hegemónicos convive (no exento de conflictos) junto al agravamiento de la problemática social y ambiental del resto de la población.

¿Existe alguna relación entre la acumulación por desposesión y los derechos humanos básicos como, por ejemplo, la salud pública? Harvey (2006, s/p) nos recuerda que, en última instancia, la acumulación por desposesión no es sino 'el saqueo y robo de los derechos de las personas'. La vulneración y el avasallamiento de los derechos humanos básicos parecen haberse erigido, de hecho, en la última frontera del capitalismo. En el caso de la salud pública, la relación con los mecanismos capitalistas de despojo suele ser pensada en términos de mercantilizacióny privatización de serviciosy prestaciones sanitarias, y la consiguiente metamorfosis de ese bien común social en un objeto de lucro privado. A pesar de la evidente importancia de ese enfoque, los nexos entre acumulación por desposesión y salud no se agotan allí.

¿Qué ocurre, por ejemplo, cuando ciertas formas de acumulación capitalista suponen una amenaza directa para la salud de la población y atentan incluso contra la reproducción de la vida humana? ¿Acaso no se vuelto cada vez más habitual que ciertos usos del territorio o determinados modelos de modernización despojen a comunidades enteras de su derecho connatural a la salud? Los usos modernos del territorio son a menudo irracionales para la mayor parte de la sociedad, excepto para los agentes hegemónicos beneficiados por ese modelo de organización espacial; el territorio se valoriza para el capital, pero paralelamente se torna menos valioso para los hombres; el orden funcional y egoísta creado por las empresas hegemónicas se traduce en desorden para el resto de la sociedad local (Santos y Silveira, 2001, p. 116, 130 y 258). Esto genera un insoluble y cada vez más asiduo conflicto entre la preeminencia de algunas formas globalizadas de acumulación capitalista y la reproducción del derecho a la salud -a la vida, a la existencia- intrínseco a la población local. En otro lugar, este fenómeno ha sido denominado 'desposesión del derecho a la salud' (Gómez Lende, 2015, p. 59).

Siguiendo a Beck (1998, p. 44-45), la destrucción de la naturaleza - degradación del suelo, pérdida de biodiversidad, contaminación del aire, el agua y el suelo, etc, el deterioro de los alimentos y los accidentes (químicos, tóxicos, nucleares) son formas de 'expropiación ecológica' que afectan no sólo a las formas biológicas que viven en esos elementos, sino también a todos los seres humanos que viven de ellos. Esto se ha vuelto cotidiano en el sistema capitalista actual, donde es cada vez más habitual que aquello que por un lado hace crecer la productividad, por el otro acabe provocando enfermedades (Beck, 1998, p. 68). Eso explica la estrategia de los países ricos industrializados, que externalizan los riesgos ecológicos y sanitarios de producir ciertos bienes a las naciones del Tercer Mundo, para luego importar esos mismos productos a buen precio (Beck, 1998, p. 29 y 50). En consecuencia, la desposesión del derecho a la salud mediada por la acumulación del capital y el intercambio desigual no es igualitaria: la primera ley ambiental es que 'la contaminación sigue al pobre' (Beck, 2001, p. 8).

En ese sentido, parte del respaldo de los Estados de los países periféricos a la acumulación por desposesión consiste en legitimar y naturalizar ciertos riesgos ecológico-sanitarios. Las empresas operan en la sombra sin responsabilidad alguna por las consecuencias de sus actos, en tanto la política 'depura' a éstas de sus 'daños colaterales', a la vez que neutraliza las denuncias y presiones que pudieran afectar a los intereses económicos en juego (Beck, 1998, p. 268). So pretexto de 'utópica', la obvia exigencia social de impedir el envenenamiento es así rechazada por el Estado, quien la suplanta por una medida permitida - un valor límite de tolerancia - o, lo que es igual, por una 'ración duradera de envenenamiento colectivo normalizado'(Beck, 1998, p. 73). 
Bajo la égida del actual modelo de agricultura industrial (el llamado 'agro-negocio'), el uso intensivo de plaguicidas constituye una pieza clave y significativa de ese 'envenenamiento colectivo normalizado'. Según la Organización Mundial de la Salud (OMS), el número de envenenamientos con agro-tóxicos se situó, entre la década de 1980 y comienzos del Siglo XXI, en el orden de los 3 millones de casos anuales, con una mortalidad de 220.000 personas/año; en las naciones del sur, la tasa era 13 veces mayor a la de los países industrializados, con un altísimo nivel de sub-registro - en general, 25 millones de casos no declarados - (GRR, 2009, p. 208). Esto se torna evidente en la Argentina contemporánea, donde el modelo de organización espacial asociado al monocultivo de soja transgénica opera como una forma de acumulación por desposesión en diversas dimensiones de la vida social, incluida la esfera sanitaria.

\section{Modelo sojero y acumulación por desposesión en la Argentina}

Las reformas neoliberales implementadas en la Argentina durante la década de 1990 implicaron la apertura importadora, la liberalización financiera, los flujos masivos de Inversión Extranjera Directa (IED), la privatización de empresas públicas, la desregulación de mercados y la reprimarización del aparato productivo. En el campo y la agroindustria, esas políticas desmantelaron diversos mecanismos de control estatal - precios mínimos y máximos, cupos de siembra, cosecha y comercialización, entes reguladores (Junta Nacional de Granos, Corporación Nacional de Productores de Carnes, etc) -, a la vez que propiciaron el surgimiento de un nuevo modelo agroalimentario, basado en la profundización de la integración vertical de la producción, la mayor difusión de la agricultura bajo contrato, la concentración de la tierra y el capital, el auge de los Organismos Genéticamente Modificados (OGM's) y la desaparición de las prácticas de rotación agropecuaria. El pilar y motor que subyace a esa reestructuración ha sido, indudablemente, el boom de la soja transgénica, concretamente la variedad RR resistente al herbicida glifosato de amonio - .

La soja RR y el paquete tecnológico que la acompaña fueron introducidos al país por la empresa transnacional biotecnológica y agroquímica Monsanto y sus licenciatarias Asgrow y Nidera. La semilla se propagó ilegalmente - vía contrabando genético y plantaciones clandestinas - hasta que en 1996 el Estado nacional aprobó formalmente su siembra. Como resultado, la superficie implantada creció un 196,6\% entre 1996/97 y 2013/14 - pasó de 6.669 .572 a 19.781 .812 has -; en idéntico lapso, la producción aumentó un 385,2\% - de 11.004.890 a 53.397.710 tn - (Argentina, 2015a).

La fiebre sojera no se limitó a la 'pampa húmeda' - provincia de Buenos Aires, sur de Santa Fe, Córdoba y Entre Ríos, y norte de La Pampa -, sino que también conquistó áreas agrícolamente marginales - norte santafesino, cordobés y entrerriano, este de San Luis, provincias de Corrientes, Misiones, Jujuy, Chaco, Santiago del Estero, Tucumán, Formosa y Salta (FIGURA 1). Su rápida expansión obedeció a factores externos - crisis sanitaria mundial de la ganadería, aumento de la demanda de proteínas vegetales, escalada del precio internacional de oleaginosas- e internos - tecnificación y cientifización del trabajo agropecuario, difusión de la siembra directa, cambio del régimen de lluvias, crisis de producciones tradicionales (ganadería, caña de azúcar, algodón), posibilidad de transportar la producción por la Hidrovía Paraná-Paraguay -.

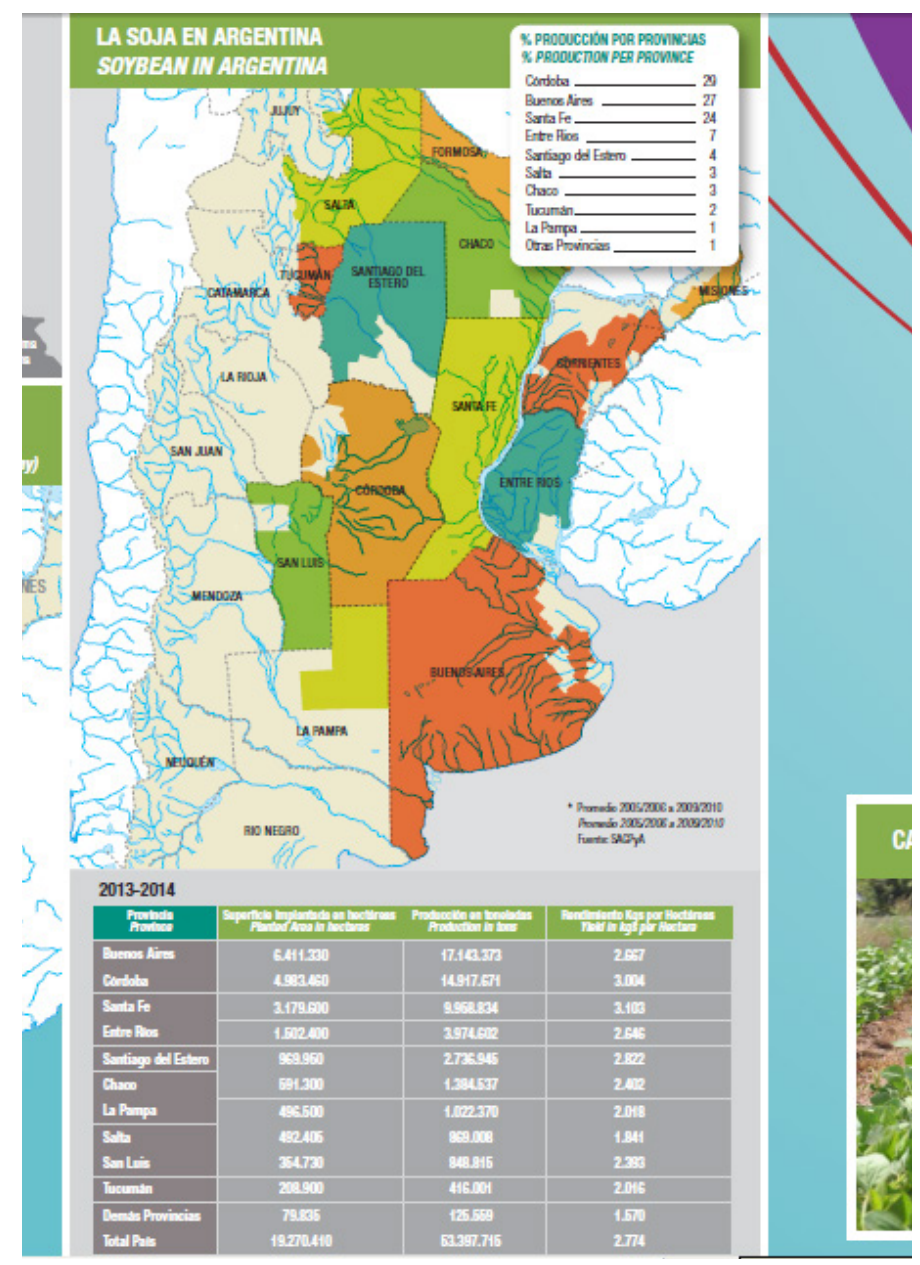

FIGURA 1 Cultivo de soja en la Argentina. Campaña agrícola 2013-2014. Fuente: Argentina (2015b)

Otrora poco más que una 'rareza botánica' (Pengue, 2005 , p. 83), la soja representa actualmente casi el $60 \%$ del área implantada, más de la mitad de la producción de granos y el 27,7\% de las exportaciones (Argentina, 2015a; 2015c). En consecuencia, el país se ha convertido en el tercer productor mundial de porotos de soja - después de los Estados Unidos y Brasil - y el principal comercializador de aceites y harinas (Pierri, 2006, p. 62). La soja es un cultivo esencialmente de exportación; el 95\% de la producción doméstica se destina a mercados internacionales como China, India, Holanda, Irán, Pakistán, Bangladesh y Japón (Pierri, 2006, p.62; Teubal y Palmissano, 2013, p.51). Aunque 
el negocio se concentra básicamente en firmas globales - Cargill, Bunge, Louis Dreyfus - y argentinas - Vicentín, Pérez Companc, Aceitera General Deheza-, el Estado nacional participa de esa renta agroindustrial a través de retenciones a las exportaciones $-25 \%$ durante el período 2003-2008, 35\% desde 2008 hasta la actualidad-; esto le permite resolver desequilibrios comerciales, sostener las cuentas fiscales para el pago de los intereses de la deuda externa e invertir en infraestructura.

El modelo sojero opera bajo múltiples modalidades como un mecanismo de acumulación por desposesión. Se encuentra ampliamente documentada, por ejemplo, la existencia de diversas formas de mercantilización y despojo de la tierra, desde la concentración de la propiedad agropecuaria vía remates bancarios y nuevas formas de arrendamiento -pools de siembra-, hasta la expulsión por la fuerza de campesinos y aborígenes mediante distintas prácticas coercitivas ejercidas por distintos segmentos del Estado -fuerzas públicas de seguridad, jueces- $y$ grupos privados para-institucionales ('guardias blancas') (Argentina, 2013a, p. 13 y 16; REDAF, 2013, p. 35-44; Morina y Cacace, 2013, p. 315).

Otra forma de despojo está asociada al incremento exponencial de la degradación ambiental y la pérdida de biodiversidad. Orientada a liberar tierras fértiles para la expansión de la frontera agrícola, la tala indiscriminada arrasó con casi 5 millones de hectáreas de bosques nativos en apenas 16 años (1998-2014) (Argentina, 2007; 2014; 2015d). El 95,8\% de la superficie deforestada correspondió a provincias que pertenecen a la zonanúcleo sojera, o bien forman parte de las áreas marginales conquistadas por la expansión de dicho monocultivo. En ese mismo lapso, las tasas de desmonte en la Argentina fluctuaron entre el $0,49 \%$ y el $1,31 \%$ anual, esto es, entre 3,5 y 9,4 veces la media mundial (FAO, 2007, p. 37; 2012, p. 17; Argentina, 2007; 2014; 2015d).

Otro factor a considerar es la intensificación de la transferencia de capacidad de carga y servicios ecológicos al exterior, básicamente 'agua virtual y 'suelo virtual'. La comercialización de soja ha implicado, por ejemplo, la gratuita remesa al exterior de 42.500 millones de metros cúbicos de agua durante la campaña 2004/2005, y otros 55.000 millones de m3 en 2007/2008 (Pengue, 2006, p. 72; Merenson, 2011, p. 11). El monocultivo de soja también ha conducido al agotamiento de de los suelos, drenando importantes cantidades de nutrientes -nitrógeno, fósforo, potasio, calcio, magnesio, azufre, hierro, manganeso, molibdeno, cobre, bromo, zinc y cloro- que deben ser restituidas mediante la importación de costosos fertilizantes (Pengue, 2006, p. 72).

Sobresalen, asimismo, mecanismos de despojo como los derechos de propiedad intelectual asociados a patentes biotecnológicas y licencias de material genético y plasma de semillas. Monsanto, por ejemplo, cobra desde 1999 'regalías extendidas' a los productores sojeros; pese a la anuencia del Estado nacional, este régimen constituye una forma ilegal de acumulación por desposesión, toda vez que contraviene la ley argentina de semillas. Recientemente, esa empresa ha dispuesto que su nueva soja RR 2 Intacta Pro sólo sea adquirida por aquellos agricultores que previamente hayan firmado un contrato donde acepten expresamente pagar 'regalías extendidas' al momento de la compra; paralelamente, Monsanto apremia al Estado nacional a sancionar una ley que, además de convalidar lo anterior, derogue el uso gratuito de todas las semillas.

\section{Soja transgénica y fumigaciones con agrotóxicos en la pampa húmeda y el norte argentino: la desposesión del derecho a la salud}

En la Argentina, el modelo sojero opera además como un vector de desposesión del derecho a la salud de las comunidades locales. En el norte argentino, por ejemplo, el auge sojero y la tala forestal configuran nuevos cercamientos que han agudizado la migración masiva y compulsiva de campesinos y aborígenes hacia ciudades y pueblos próximos donde pasan a engrosar los abultados cinturones de pobreza y miseria. Obligados a morar en la periferia de algunas ciudades salteñas, chaqueñas, santafesinas y formoseñas, esos grupos sociales se alimentan en basurales y padecen hambre, sed, desnutrición, elevados niveles de mortalidad infantil y alta incidencia de enfermedades zoonóticas propias del ámbito selvático (hanta virus, dengue, leishmaniasis) que migraron a las urbes como consecuencia de la deforestación (Delgado, 2008, p. 148-152; Naharro y Álvarez, 2011, p. 23-28; Gómez Lende y Velázquez, 2013, p. 49-50).

No obstante, la problemática sanitaria más aguda ligada al modelo sojero se ha desarrollado en el marco de las fumigaciones con agro-tóxicos. Lo que Silveira (2003, p. 76) Ilama 'quimificación de la agricultura' ha recrudecido en la Argentina a partir del boom de la soja transgénica. El consumo de agro-tóxicos aumentó un 858\% entre 1991 y 2012 -pasó de 39 millones a 335 millones de litros/año- (REDUAS, 2013, p. 1-2, en base a CASAFE). A diferencia de otros países, donde el límite establecido para el uso de agroquímicos es de 3 litros por hectárea, en la Argentina se aplican hasta 12 Its/ ha, con casos extremos como los de las provincias de Santiago del Estero y Chaco -20 Its/ha- ${ }^{1}$ (REDUAS, 2013, p. 1; Pérez, 2015). A nivel nacional, esto implicaría una dosis potencial de exposición a plaguicidas de 8 litros por habitante (REDUAS, 2013, p. 3). Como resultado, el mercado agroquímico argentino reporta a las empresas del sector

1 Esto no habría sido posible sin la complicidad del Estado nacional, autorizó que el límite máximo tolerado de presencia de residuos de agroquímicos en cultivos y alimentos aumentara 100 veces -pasó de 0,2 partes por millón a 20 partes por millón-. 
una facturación de 2.500 millones de dólares anuales (Eleisegui, 2015).

El paquete tecnológico de la soja gira en derredor del glifosato de amonio, un herbicida de acción global comercializado por empresas químico-biotecnológicas extranjeras como Monsanto, Syngenta, Basf, Bayer, Dupont, Dow Agrosciences,Nidera y Atanor. El uso de este producto creció vertiginosamente, representando en la actualidad el $64 \%$ de las ventas generales de agroquímicos (REDUAS, 2013, p.2, en base a CASAFE). En 2009, sus niveles de aplicación superaban los 5 Its/ha en buena parte del área sojera nacional (FIGURA 2). Este agrotóxico no se utiliza aisladamente, sino combinado con otros herbicidas, insecticidas, cura-semillas y funguicidas - 2,4-D, cipermetrina, endosulfán, clorpirifós, paraquat, hexaclorobenceno, malatión, heptacloro, glufosinato de amonio, bromoxynil, atrazina -. Es importante destacar que el uso de algunos de los agroquímicos mencionados se encuentra restringido en varios países ${ }^{2}$, y que en 2009 la Comunidad Económica Europea prohibió -a pedido del Parlamento Europeo- la realización en su territorio de fumigaciones aéreas de cualquier índole.

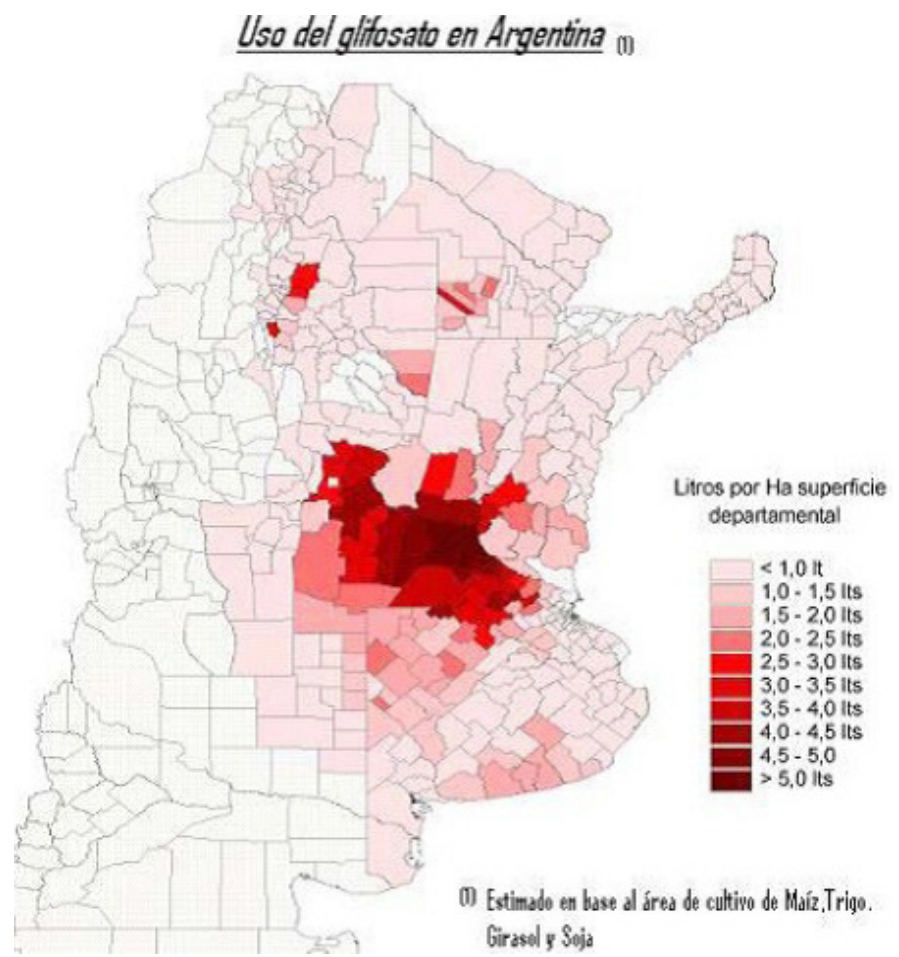

FIGURA 2: Uso del glifosato en la Argentina (en litros por hectárea) Fuente: Argentina (2009).

Las fumigaciones aéreas y terrestres con estos agro-tóxicos han ocasionado graves perjuicios sociales,

\footnotetext{
$\overline{2}$ Tristemente célebre por ser el principio activo del 'agente naranja' utilizado por el ejército estadounidense en la guerra de Vietnam, el 2,4-D ha sido prohibido en Dinamarca, Suecia y Noruega. Insecticida extremadamente peligroso, el endosulfán ha sido prohibido en 60 países, entre los cuales sobresalen Dinamarca, Alemania, Holanda, Suecia, Belice, Singapur y el estado brasileño de Rondonia; el uso de este producto -que ha sido clasificado como 'restringido a severamente restringido' en Canadá, Finlandia, Gran Bretaña, Kuwait, las Filipinas, Rusia, Sri Lanka, Madagascar y Tailandia- fue prohibido en 2012 en la Argentina. Otro caso es el de la atrazina, prohibida en Europa a partir de 2004. Otros agro-tóxicos, como el heptacloro y el hexaclorobenceno, han sido prohibidos en buena parte del mundo -incluida la Argentina(Gallo, 2010, p. 2-3; Montenegro, 2009; Eleisegui, 2015; Pérez, 2015). No obstante todos estos productos continúan siendo de uso habitual en la agricultura argentina.
}

económicos, ambientales y sanitarios en las localidades rurales de diversas provincias argentinas. Se han reportado incontables casos de destrucción de cultivos hortícolas y colmenas, mortandad y/o enfermedad degenerativa de aves de corral y ganado, pérdida de biodiversidad -especialmente, fauna silvestre- $y$ contaminación del aire, el suelo y las aguas superficiales y subterráneas. En 2013, un exhaustivo relevamiento informó la existencia de 258 conflictos ambientales en las provincias de Chaco, Santiago del Estero, La Rioja, Catamarca y Tucumán, el este de Salta, el norte de Santa Fe y San Luis, y el noroeste de Córdoba y Corrientes, esto es, el epicentro de la más reciente y agresiva expansión del monocultivo de soja transgénica; el $49 \%$ de los casos correspondía a la contaminación por uso de agrotóxicos, que afectaba a 461.828 personas en una superficie de 3.417.448 hectáreas (REDAF, 2013, p.63 69). Otras fuentes estiman que el número de afectados en todo el país ascendería a 12 millones de personas - el $30 \%$ de la población argentina- que, distribuidos entre las provincias de Buenos Aires, Santa Fe, Córdoba, Entre Ríos, Santiago del Estero, San Luis, Chaco, Salta, Jujuy, Tucumán, La Pampa y Corrientes, padecen las consecuencias de la realización de 50 fumigaciones/ año - con una media de entre 30 y 60 litros de agrotóxicos por habitante - (REDUAS, 2010, p. 30; Pérez, 2015; Eleisegui, 2015).

Según Montenegro (2009), la Argentina sufre una epidemia silenciosa debido al uso regular $\mathrm{e}$ indiscriminado de plaguicidas. Se han documentado innumerables casos de patologías ocasionadas por la exposición a agro-tóxicos en provincias sojeras como Buenos Aires, Córdoba, Santa Fe, Entre Ríos, Chaco, Formosa y Salta. No obstante, la magnitud de esa problemática resulta difícil de evaluar, en virtud de la relativa escasez relevamientos oficiales espacializados de morbi-mortalidad; durante mucho tiempo, la principal fuente de información se ha limitado a relevamientos y censos desarrollados por las propias comunidades locales, elaborados en base a formularios de epidemiología popular (Montenegro, 2009). Existen fuertes niveles de sub-registro, debido a la ausencia de datos epidemiológicos certeros y la escasez de estudios de población in situ.

Hasta el momento, el único informe oficial con el que se cuenta es un estudio multidisciplinario financiado por el Ministerio de Salud de la Nación y desarrollado a comienzos del Siglo XXI en una localidad del norte bonaerense y cinco pueblos del sur santafesino. Los investigadores hallaron vinculaciones directas entre la incidencia de cáncer y malformaciones infantiles, y la exposición a contaminantes ambientales. El estudio reportó que - amén de afecciones respiratorias, leucemia, interrupciones de embarazos y malformaciones urogenitales masculinas -, los casos de cáncer de 
páncreas y pulmón duplicaban el promedio nacional, y las neoplasias malignas testiculares y gástricas lo triplicaban; asimismo, la incidencia del cáncer de hígado se hallaba diez veces por encima de la media nacional. En el $90 \%$ de los casos, las patologías detectadas estaban ligadas a fuentes fijas de contaminación o factores ambientales de riesgo, entre los cuales sobresalían las fumigaciones con agro-tóxicos, los depósitos de almacenamiento de plaguicidas y/o equipos de fumigación, y las plantas y silos de acopio de granos (Página 12, 2006; Joensen, 2008, p. 72; GRR, 2009, p. 55-56) ${ }^{3}$.

A nivel nacional, la gravedad de la situación y la desidia estatal dieron lugar a la creación en 2010 de la Red Universitaria de Ambiente y Salud/Médicos de Pueblos Fumigados (REDUAS), integrada por profesionales que atienden a las mismas poblaciones desde hace más de 25 años. Sus relevamientos han establecido fuertes correlaciones empíricas entre las fumigaciones con agro-tóxicos y el notable incremento de los casos registrados de afecciones otrora infrecuentes, como malformaciones congénitas, abortos espontáneos, eclampsias e hipertensión arterial durante el embarazo, leucemias, distintos tipos de cáncer en niños y adultos, afecciones respiratorias, reducción de la talla de crecimiento y del desarrollo en la infancia, disrupciones hormonales, mutagénesis, lupus, esterilidad masculina, anemia, daños en el sistema nervioso central, púrpuras, esclerosis múltiple, isquemia cerebral, hepatopatías tóxicas y trastornos neurológicos, entre otras (REDUAS, 2010, p. 3-4; Eleisegui, 2015).

Según estudios realizados en 25 localidades de menos de 15.000 habitantes de Santa Fe, Córdoba y Entre Ríos, el cáncer era responsable por una de cada tres muertes; esto muestra un significativo desfase respecto de los valores promedio a escala nacional, toda vez que en la Argentina la primera causa de mortalidad son las enfermedades cardiovasculares (26\%), no las patologías oncológicas (20\%). En las localidades relevadas, la incidencia del cáncer era tres veces mayor a la de las áreas urbanas, y la población afectada era mucho más joven de lo esperable. Los estudios constataron, además, que los problemas respiratorios y endocrinos duplicaban las cifras medias, la tasa de abortos espontáneos oscilaba entre el $10 \%$ y el $22 \%$ de las mujeres en edad reproductiva, y la incidencia de los nacimientos con malformaciones triplicaba las tasas registradas en otras áreas del país (Pérez, 2015) ${ }^{4}$. Se

${ }^{3}$ Ese estudio fue realizado por el Centro de Investigaciones en Biodiversidad y Ambiente del Hospital Italiano Garibaldi de Rosario, la Universidad Nacional de Rosario, el Instituto Nacional de Tecnología Agropecuaria, el Colegio de Ingenieros Agrónomos y la Federación Agraria Argentina.

${ }^{4}$ Existe una antigua explicación epidemiológica que atribuye la incidencia del cáncer en los pueblos del interior de la Argentina a determinados atributos socio-demográficos, como la edad y el envejecimiento poblacional o la situación de vida. Sin embargo, estudios más recientes demuestran que el patrón de riesgo de estas patologías -sobre todo, cáncer gástrico y de próstata- ha cambiado, comenzando a afectar con más fuerza a la población de mediana edad e, incluso, a la población joven (infantil y adolescente) (GRR, 2009, p. 22). reportaron, asimismo, índices de 12 malformaciones cada 250 nacimientos en localidades como Montecristo (Córdoba), San Cristóbal, Las Petacas y Malabrigo (Santa Fe) (Carrasco, 2011).

Otro caso relevante es el de la localidad entrerriana de San Salvador, antaño vinculada a la producción de arroz y actualmente conquistada por el monocultivo sojero. Equipos de investigación pertenecientes a las Universidades de La Plata y Rosario realizaron en 2014 un estudio epidemiológico-ambiental cuyas conclusiones sindicaron al cáncer como causa del $45 \%$ de los fallecimientos registrados entre 2010 y 2013 -más del doble que la media nacional - (Eleisegui, 2015). Anteriormente, 60.000 pobladores del centro provincial -en particular, de la localidad de Villaguayresponsabilizaban a las fumigaciones con endosulfán por trastornos como diarrea, mareos, cefaleas, náuseas, dificultades respiratorias, afecciones dermatológicas y aumento del número de casos de malformaciones congénitas en neonatos muy superior a los valores normales. Sólo entre 2000 y 2005, la incidencia de afecciones digestivas (diarrea) y respiratorias (neumonía, influenza) vinculadas con el uso intensivo de agro-tóxicos se duplicó entre los habitantes entrerrianos (Joensen, 2008, p. 168 - 169).

Nuevos estudios epidemiológicos, esta vez realizados en localidades sojeras del norte santafesino, comprobaron que las tasas de cáncer (de mama, próstata y pulmón) duplicaban y hasta cuadruplicaban el promedio nacional, registrando además de problemas respiratorios crónicos y elevados índices de trastornos en la glándula tiroides (Pérez, 2015). Otro caso paradigmático (y tristemente célebre) es el de la localidad de Las Petacas (Santa Fe), donde a la elevada incidencia de casos de cáncer se le añade la contaminación del agua potable con arsénico, nitratos, nitritos y productos fosforados provenientes de los agro-tóxicos (Joensen, 2008 , p. 174). Lo anterior se ve agravado, además, por las prácticas de algunos productores sojeros, que utilizan a niños menores de 16 años como banderilleros para las fumigaciones de cultivos con glifosato, 2,4$D$ e insecticidas, pagándoles entre $\$ 0,20$ y $\$ 0,50$ por hectárea (GRR, 2009, p. 53-54).

Peralta et al (2011, p. 18 y 23), por su parte, hallaron una significativa correlación entre el modelo sojero y la incidencia de patologías graves en la localidad cordobesa de Marcos Juárez: en el $56,3 \%$ de los casos observaron afecciones respiratorias, dermatológicas, digestivas y neurológicas crónicas; el $40 \%$ de las mujeres encuestadas refirió trastornos reproductivos (básicamente, abortos espontáneos); y todas las personas analizadas habían sufrido daños genéticos debido a la exposición a plaguicidas.

No obstante, el caso más resonante ha sido, indudablemente, el del Barrio Ituzaingó Anexo de 
la ciudad de Córdoba. Literalmente rodeado por sembradíos de soja, este barrio periférico de la capital provincial fue declarado en emergencia sanitaria en 2002, luego de casi una década signada por el alarmante aumento de casos de cáncer y otras enfermedades graves entre sus 5.000 residentes $^{5}$. Los propios pobladores efectuaron relevamientos sanitarios, que arrojaron como resultado guarismos muy significativos para un muy amplio espectro de patologías, como lupus, púrpura, anemia hemolítica, enfermedad de Hodking, artritis reumatoide, alergias respiratorias y dérmicas, enfermedades neurológicas y endocrinas, diversas malformaciones -Síndrome de Fryn, espina bífida, anomalías renales, osteogénesis, nacimientos de niños sin maxilares, sin diafragma o con un número anormal de dedos-y distintos tipos de cáncer -leucemia, mamas, estómago, garganta- entre los adultos y, sobre todo, la población infantil y adolescente del asentamiento (Joensen, 2008, p. 184; GRR, 93, 96 y 99).

$\mathrm{Si}$ bien el Barrio Ituzaingó Anexo había sido edificado sobre terrenos previamente contaminados -un antiguo predio industrial abandonado-, pudo probarse empíricamente que la exposición a agro-tóxicos constituía el factor de riesgo más importante: por un lado, a menor distancia respecto de los sembradíos de soja, mayor incidencia de los casos de cáncer, leucemia y trastornos tiroideos; por otrolado, dos estudios realizados en 2006 y 2010, respectivamente, constataron que el $80 \%$ de la población infantil presentaba agroquímicos organoclorados en sangre. En consecuencia, la Justicia provincial primero, y la intendencia municipal después, prohibieron la aplicación de agro-tóxicos a menos de 2.500 metros de las viviendas (Joensen, 2008, p.181; GRR, 2009, p.91; REDUAS, 2010, p.3 y 31; Pérez, 2015).

Otros ejemplos dignos de consideración son la localidad bonaerense de Chacabuco y la ciudad santafesina de San Lorenzo. En el primer caso, se registró un alarmante aumento de los casos de cáncer, enfermedades respiratorias y neurológicas, diferentes tipos de alergias, patologías dermatológicas, malformaciones y abortos espontáneos. En el segundo, se observó un sustancial aumento del número de enfermedades oncológicas, dermatológicas y respiratorias, así como también una incidencia de los casos de leucemia que duplicaba la media mundial; estudios posteriores confirmaron la presencia de hexaclorobenceno, hexacloro, adrin y endosulfán en el suelo, el agua y la atmósfera - polvillo de granos - (GRR, 2009 , p. 41, 44 y 50). En el sur santafesino, donde se emplaza el complejo sojero agroindustrial - portuario más grande del mundo, habitantes de poblados linderos a campos de soja han denunciado un notable incremento de los casos de enfermedades graves y nacimientos con

${ }^{5}$ Sobre ese total, 200 habitantes del barrio padecían cáncer. Todas las familias residentes contaban con un integrante afectado por alguna patología grave o inusual (GRR, 2009, p. 91) malformaciones; paralelamente, el Sindicato de Peones Rurales reportó un aumento de los casos de cáncer entre los trabajadores agrarios (Joensen, 2008, p. 178-179).

Situaciones similares han sido detectadas en localidades como San Nicolás (Buenos Aires) y San Jorge (Santa Fe) (REDUAS, 2010, p. 4). En pueblos rurales del también santafesino departamento de General López, la incidencia del cáncer es un $50 \%$ mayor al promedio nacional; allí, las aplicaciones de agro-tóxicos alcanzan una media anual de 31,5 litros per cápita. En la ciudad de Hernando (Córdoba), los resultados de un estudio de la Secretaria de Salud Municipal revelaron un aumento del $258 \%$ en los casos de enfermedades oncológicas en apenas una década (REDUAS, 2013, p. 4).

El relevamiento epidemiológico más reciente ha sido el efectuado por la Universidad de Córdoba en la localidad sojera Monte Maíz. Sobre un universo de casi 5.000 personas (el $62 \%$ de la población), dicho estudio reportó que la tasa bruta de incidencia de cáncer (707,64/100.000 habitantes) duplicaba el promedio provincial y triplicaba la media nacional (217/100.000 habitantes); de hecho, esta enfermedad constituía la primera causa de defunciones, con marcada participación de la población joven y una tasa de mortalidad que triplicaba el promedio general. Además, se constató fuerte incidencia de neumopatías, hipotiroidismo, malformaciones congénitas y abortos espontáneos; la presencia de casos de lupus, artritis reumatoide e hipotiroidismo duplicaba la frecuencia esperable, en tanto que las tasas de malformaciones congénitas $(2,93 \%)$ y abortos espontáneos $(9,98 \%)$ se hallaban un $72 \%$ y $332 \%$ por encima de las respectivas medias nacionales ( $1,7 \%$ y $3 \%$ ). La relación con el modelo sojero es innegable: los niveles de contaminación con agroquímicos alcanzaban los 630.000-975.000 litros/ año; la mayor incidencia de neumopatías correspondía a la población más cercana al área de acopio de granos; y se detectó la presencia de glifosato, cipermetrina, clorpirifós, 2,4-D y atrazina en las muestras de suelo y cascarillas de granos presentes en el aire (Ávila Vázquez et al, 2013, p.1 - 23; 2015; Eleisegui, 2015).

La realidad cotidiana de los denominados 'pueblos fumigados' de la pampa húmeda ilustra una miríada de contradicciones sociales. Como explica Joensen (2008, p. 177), la inmensa mayoría de los pueblos rurales de provincias como Buenos Aires, Córdoba y Santa $\mathrm{Fe}$ no cuenta con emprendimientos fabriles de peso; la única actividad económica rentable es la agricultura, estructurada básicamente en torno al monocultivo de soja, que a su vez ha arrasado literalmente con usos del territorio pretéritos -producciones agrícolas y pecuarias tradicionales-. La vida económica de esas localidades depende estrechamente del modelo sojero, cuyos ritmos y coyunturas marcan el pulso del comercio, la construcción de obras de infraestructura y la actividad 
inmobiliaria. Esa paradoja expresaría, en términos de Beck (1993, p. 47-48 y 56), una suerte de contrapunto entre, por un lado, la fuerza adhesiva del miedo ante la amenaza invisible de la muerte por intoxicación -protagonizada en este caso por las fumigaciones con agro-tóxicos- $y$, por el otro, la dependencia respecto de un modelo productivo que, si fuera desarticulado, podría conducir a la visible amenaza de la miseria material.

Este escenario no se limita apenas a la pampa húmeda; casos similares han sido registrados en las provincias del norte argentino a raíz del agresivo e implacable avance de la frontera sojera. En la localidad de Loma Senés (Formosa), por ejemplo, los pobladores han denunciado episodios de mareos, náuseas, vómitos, diarreas, dolor estomacal, erupciones y sarpullidos, alergias, lesiones dérmicas, irritación de ojos y problemas de la visión, inmediatamente después de la fumigación de los campos de soja cercanos a sus viviendas (Joensen, 2008, p. 167). Delgado (2008, p. 149 - 150) informa que, de acuerdo a las estadísticas centralizadas del Hospital San Bernardo de Salta -el nosocomio más grande de dicha jurisdicción-, los casos de cáncer aumentaron un $300 \%$ en apenas diez años, en su mayoría provenientes de los principales departamentos sojeros de la provincia; se registró, además, una alarmante proporción de neonatos afectados por malformaciones congénitas, leucemia y otros tipos de cáncer, todas ellas patologías que años atrás eran prácticamente desconocidas en el medio rural salteño.

Otro caso es el de la provincia del Chaco, donde un estudio epidemiológico que relevó a 2.051 habitantes pertenecientes a seis poblados reportó una altísima proporción de malformaciones congénitas -deformaciones del cerebro, médulas espinales expuestas, ceguera, sordera, lesiones neurológicas-, infertilidad y problemas inusuales de piel. Esos resultados coincidían respecto de los registros hospitalarios provinciales, donde los certificados de nacimiento demostraban que, entre 1997 y 2008 -período de expansión de la siembra de soja y, en menor medida, algodón transgénico-, la incidencia de defectos congénitos en neonatos se había cuadruplicado -pasó de 19,1 a 85,3 casos cada 10.000 nacimientos-. La prevalencia del cáncer infantil casi se había duplicado, pasando de 8,03 afectados cada 100.000 nacimientos en 1991 a 15,07 enfermos cada 100.000 alumbramientos en 2007. La relación con el modelo sojero era evidente: la incidencia de todas las patologías citadas era mucho mayor en las localidades agrícolas que en los pueblos ganaderos; la mortalidad por malformaciones, anomalías cromosómicas y deformidades era más alta en las zonas sojeras; y la incidencia de cánceres infantiles era mucho más significativa en los pueblos más afectados por las fumigaciones con agro-tóxicos (REDUAS, 2010, p. 7-12; Pérez, 2015).
Tanto en la pampa húmeda como en el norte argentino, todos los estudios realizados coinciden en reconocer los mismos factores de riesgo: manejo desaprensivo de plaguicidas; elevados niveles de toxicidad de los agroquímicos utilizados; creciente volumen de las aplicaciones de agro-tóxicos; cambios en la composición química de los mismos, debido a la aparición de resistencia o tolerancia al producto en ciertas especies de malezas y/o plagas ${ }^{6}$; inclusión de sustancias aún más peligrosas, a menudo desconocidas 7 ; fumigación aérea rutinaria a gran escala desde aviones y 'mosquitos'; las condiciones climáticas ${ }^{8}$, y cercanía de los sembradíos de soja a las áreas pobladas, pese a que algunas legislaciones provinciales que establecen claramente distancias mínimas a respetar en función de la toxicidad y modalidad de aplicación del producto9.

En la mayoría de las localidades santafesinas se cultiva soja no sólo en la banquina de las rutas, sino incluso en los límites y el interior del propio ejido; es habitual la circulación de aparatos fumigadores y la existencia de silos de acopio de granos y depósitos de agroquímicos dentro del perímetro urbano. Se han detectado incluso fumigaciones de sembradíos de soja a 300 metros de jardines de infantes, y silos situados a apenas 20 metros de la escuela del pueblo. Algunos poblados han sido literalmente cercados por los sembradíos emplazados a muy corta distancia de las viviendas (5 - 100 metros) (GRR, 2009, p. 39 y 173 - 174). Los individuos más afectados suelen ser los habitantes de los barrios periféricos, que inmediatamente después de las fumigaciones reportan enfermedades respiratorias y eczemas (Delgado, 2008, p.150; Joensen, 2008, p.167; GRR, 2009, p.22). Esto corrobora la tesis de Beck (2001, p. 8) de que las principales víctimas en el reparto de riesgos y contaminación son los pobres. Queda claro, pues, que el modelo sojero representa una grave amenaza para la salud pública, demostrando empíricamente cómo la agricultura ha mutado de 'estamento alimenticio' y fuente imprescindible de sustento a 'reino de los venenos' que atentan contra la vida de plantas, animales y seres humanos; las 'cadenas de efectos secundarios' analizadas

\footnotetext{
${ }^{6}$ Véase el caso del glifosato de amonio. Obstando el crecimiento exponencial del volumen aplicado, su composición química se ha vuelto más agresiva: cuando recién se introdujo en el mercado, el principio activo de este agro-tóxico representaba el $41 \%$ del producto; actualmente, supera el 74\% (GRR, 2009, p. 210).

7 Salvo contadas excepciones, la mayoría de los plaguicidas no son 'sustancia pura' ni 'principio activo puro', sino que más bien constituyen complejos de sustancias químicas (Montenegro, 2009). Ejemplo de ello son los llamados 'componentes inertes', generalmente surfactantes añadidos para incorporar lipo-solubilidad al producto y no explicitados en los marbetes de los envases debido a que las empresas fabricantes los consideran 'secreto comercial' (GRR, 2009,p. 2010). En el caso del glifosato, sobresalen los casos del surfactante POEA, más letal que el propio herbicida, y la isopropilamina, sustancia destructiva de la membrana mucosa y de las vías respiratorias superiores (Morina, 2010,p. 7-8)

${ }^{8}$ Las condiciones climáticas reinantes en gran parte del área sojera argentina (elevada temperatura y humedad, viento) determinan que las fumigaciones no respeten las normas internacionales de la FAO.

${ }^{9}$ Entre Ríos y Santa Fe establecen una distancia de 3.000 metros para fumigaciones. En el caso de Córdoba, la aplicación aérea de agro-tóxicos puede realizarse en un radio de 1.500 respecto del límite de los ejidos urbanos, en tanto que el límite para las fumigaciones terrestres es de 500 metros (Saulino, 2013, p. 258). Otras provincias han prohibido uso por completo el uso de 2,4-D (Tucumán), o bien han impedido su aplicación aérea (Chaco) (Gallo, 2006, p.-3).
} 
por las ciencias técnicas se han convertido, al otro lado del muro, en voces y ojos, caras y lágrimas (Beck, 1998, p. $61-62,68,72$ y 88 ).

Existe abundante evidencia científica acumulada a nivel internacional respecto de la correlación entre las patologías mencionadas y las fumigaciones con agrotóxicos ${ }^{10}$.

En 2009, el Laboratorio de Embriología Molecular de la Facultad de Medicina de la Universidad Nacional de Buenos Aires confirmó que el glifosato de amonio producía malformaciones (teratogénesis), hinchazón de pulmones, neumonía, irritación de ojos y piel, destrucción de glóbulos rojos, trastornos intestinales y cardíacos, malformaciones y alteraciones neuronales, y cáncer. Cediendo al lobby de Monsanto ${ }^{11}$ y otras empresas del sector, el propio Poder Ejecutivo Nacional desacreditó dichos hallazgos (Morina, 2010, p. 7), aunque más tarde éstos fueron corroborados por otros investigadores argentinos y franceses $^{12}$ (Análisis Digital, 2015; Eleisegui, 2015). Recientemente, la Organización Mundial de la Salud (OMS) clasificó al glifosato como cancerígeno ${ }^{13}$. El típico y falseado enfoque donde la ciencia fija los riesgos y desacredita la percepción de la población (Beck, 1993, p. 36 y 64-65) comienza a ser paulatinamente desmontado.

Operando como un uso del territorio funcional al orden global y la división internacional del trabajo, el modelo sojero retroalimenta asimismo el intercambio desigual entre el Norte y el Sur, obligando a este último a asumir el papel de amortiguador sanitario de los excesos del sistema capitalista mundial. No obstante, algunos de los países centrales en principio beneficiados por ese patrón de acumulación también acaban siendo afectados por el despojo del derecho a la salud. Tal es el caso de China, principal importador de la soja argentina, donde esta

${ }^{10}$ Sólo en el caso del glifosato, existen a nivel mundial alrededor de 400 citas de trabajos científicos sobre su toxicidad en distintos modelos animales (de laboratorio y vida silvestre) (Análisis Digital, 2015). Se ha documentado exhaustivamente que la exposición a glifosato de amonio, 2,4-D, clorpirifós, malathión, heptacloro y endosulfán puede acarrear los siguientes impactos sanitarios: disfunción de la división celular; nacimientos con malformaciones (teratogénesis); distintos tipos de cáncer, como Linfoma No Hodgkin y neoplasias malignas genitales, mamarias y de próstata; efectos neuro-tóxicos, inmuno-supresores, cito-tóxicos y hepato-tóxicos; disrupciones endocrinas, con supresión significativa de los niveles de hormona tiroidea y testosterona; daños en hígado, riñón, piel, ojos y médula espinal; disminución en la ganancia de peso del feto y menor circunferencia craneal al nacer; náuseas y vómitos; dolor de estómago; cefaleas; vértigo, convulsiones, alucinaciones, pérdida de memoria, audición, coordinación neuro-motora y conciencia; coma; infertilidad; muerte embrional y fetal; pubertad precoz; y problemas de aprendizaje y disminución del coeficiente intelectual (Montenegro, 2009).

Con respecto al glifosato de amonio, Monsanto a menudo publicita el carácter 'biodegradable' y 'ambientalmente positivo' de este 'herbicida seguro y de uso general en cualquier lugar, desde céspedes y huertos hasta grandes bosques de coníferas'. La empresa norteamericana llegó incluso al extremo de afirmar que su producto era tan inocuo como 'agua con sal', frase textualmente reproducida en declaraciones radiales por el ministro argentino de la cartera de Ciencia y Tecnología al ser increpado con respecto a la crisis socio-sanitaria desatada por el modelo sojero (Argentina Indymedia, 2011).

12 Según esos estudios, dosis fuertemente diluidas -entre 1.000 y 100.000 veces inferiores a las utilizadas en la agricultura- provocan la muerte celular en pocas horas, provocando abortos, malformaciones, trastornos reproductivos, disrupciones hormonales, cáncer y teratogénesis (Análisis Digital, 2015; Eleisegui, 2015).

${ }^{13}$ En 2015 la OMS -a través de la Agencia Internacional para la Investigación sobre el Cáncer (IARC)- realizó el estudio "Evaluación de cinco insecticidas organofosforados y herbicidas", cuyas conclusiones señalaron que existen pruebas convincentes de que el glifosato puede causar cáncer y daños en ADN y cromosomas. Con la nueva evaluación, el glifosato fue incluido por la OMS en el Grupo 2A "Probablemente cancerígeno para los seres humanos", la segunda categoría más peligrosa de la nomenclatura del organismo. Esto significa que el glifosato de amonio es tan cancerígeno como el PCB y el formaldehído (Aranda, 2015). oleaginosa se ha convertido en un elemento básico de la dieta nacional ${ }^{14}$; recientemente, las autoridades de ese país convocaron a un foro mundial en Beijing para discutir el impacto de las semillas transgénicas y los agro-tóxicos y su relación con el deterioro de la salud de la población ${ }^{15}$. Es un claro ejemplo del 'efecto bumerang' señalado por Beck (1993, p. 48-50), donde países ricos inicialmente favorecidos por la externalización de riesgos y el abaratamiento de las importaciones son perjudicados por la llegada de los pesticidas incorporados a los alimentos.

\section{Conclusiones}

Operando como formas o modalidades de acumulación por desposesión, algunos usos modernos del territorio se vuelven irracionales para la mayor parte de la población. El boom de la soja transgénica constituye, en la Argentina, un claro ejemplo empírico de esa realidad: por un lado, el modelo sojero expresa el territorio de las verticalidades -mundialización del capital, producción globalizada, actividades modernas, normas internacionales, empresas extranjeras-; por otro lado, desarrolla múltiples mecanismos de acumulación por desposesión -mercantilización y despojo de la tierra, tala indiscriminada de bosques nativos, transferencia al exterior de capacidad de carga y servicios ecológicos ('agua' y 'suelo virtual'), derechos de propiedad intelectual (patentes, regalías extendidas)-. Se solapan así expropiaciones geográficas (desintegración de la matriz productiva y configuración de enclaves exportadores), económicas (transferencia de recursos financieros a los países centrales) y ecológicas (remesa de intangibles ambientales) que son respaldadas y promovidas desde el Estado.

El despojo capitalista asociado al boom sojero atenta además contra la reproducción de la propia vida humana. El objeto de esa desposesión no es la tierra, la biodiversidad, los recursos naturales o la riqueza genética; es la salud pública, entendida aquí no como un botín a conquistar o mercantilizar, sino más bien como una víctima de los 'daño colaterales' provocados por un lucrativo pero pernicioso uso del territorio. El monocultivo de soja transgénica y las fumigaciones a gran escala con agro-tóxicos constituyen una pieza fundamental del 'envenenamiento colectivo normalizado' padecido por

\footnotetext{
${ }^{14}$ El aceite de soja y el polvo de proteína de soja (un subproducto de ese mismo aceite) son incluidos en tres comidas diarias de la dieta china (REDUAS, 2014). ${ }^{15}$ Un comité de estudios estratégicos y la Universidad de Yunnan reunió a 30 científicos e investigadores de todo el mundo en el Food Safety \& Sustainable Agriculture Forum 2014, desarrollado en Beijing los días 25 y 26 de julio de ese año. Allí se discutió la relación que podrían guardar la soja y el glifosato con el deterioro de la salud de la población china: entre 1996 y 2010, la tasa de defectos en neonatos pasó del $0,87 \%$ al $1,53 \%$; en una década, la incidencia de la diabetes y la tasa de pubertad precoz en niñas habían aumentado doce y diez veces, respectivamente; la tasa de infertilidad representaba en 2012 el $15,6 \%$ de la población en edad, frente al $8 \%$ registrado en 2002 y el 3\% verificado en 1992; y la prevalencia del cáncer infantil se había incrementado sustancialmente, con un promedio de un paciente oncológico cada 10.000 niños. Cabe destacar que, sólo en 2013, las compras chinas de poroto de soja implicaban, en promedio, una carga de 1.000 miligramos de glifosato por habitante (REDUAS, 2014)
} 
diversas provincias argentinas; las localidades afectadas por esa problemática se han convertido en 'zonas de sacrificio' donde el alarmante deterioro de la salud de la población se ha constituido en uno de los precios a pagar por la inserción del país en el mercado mundial: los casos de patologías graves asociadas al uso intensivo de agroquímicos han aumentado exponencialmente a partir de la expansión de dicho cultivo; y todos los estudios citados demuestran que la incidencia de esas enfermedades se sitúa muy por encima de la media nacional y de los guarismos de registrados en ciudades grandes e intermedias, donde las cifras deberían ser presumiblemente mayores debido a la concentración industrial y otros factores de riesgo ambiental.

En síntesis, los graves perjuicios socio-sanitarios ocasionados por el boom sojero demuestran que se trata de un modelo hegemónico diseñado o planeado para ser indiferente a su entorno donde el imperio de la razón global no se limita a hacer tabla rasa de la historia pretérita local, sino que llega al extremo de vulnerar los derechos humanos más esenciales. El resultado es un antagonismo cada vez más irreconciliable entre, por un lado, ciertas formas globalizadas de acumulación capitalista y, por el otro, la propia vida.

\section{Referências}

AMIN, S. (1975) La acumulación a escala mundial: crítica a la teoría del subdesarrollo. Buenos Aires: Siglo XXI. 665 p.

ANÁLISIS DIGITAL. (2015) Científicos del Litoral alertan por los daños. Investigadores corroboran en campo los estudios de Andrés Carrasco: malformaciones en embriones expuestos al glifosato. Disponible em: http://analisisdigital.com.ar/ noticias. php?ed=1\&di=0\&no=223708. Acceso em: 18 oct. 2015.

ARANDA, D. (2015) Confirmado: la OMS ratificó que el glifosato de las fumigaciones puede provocar cáncer. Disponible

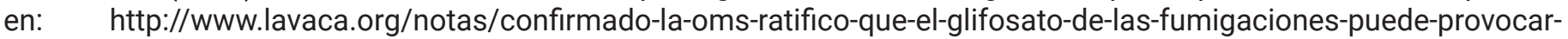
cancer/. Acceso en: 16 jul. 2015.

ARGENTINA. (2007) Informe sobre deforestación en Argentina. Buenos Aires: Secretaría de Ambiente y Desarrollo Sustentable de la Nación. 10 p.

ARGENTINA. (2009) Informe-Evaluación de la información científica vinculada al glifosato en su incidencia sobre la salud humana y el ambiente. Buenos Aires: Consejo Científico Interdisciplinario-CONICET y Ministerio de Salud de la Nación. 135 p.

ARGENTINA. (2013) Relevamiento y sistematización de problemas de tierra de los agricultores familiares en la Argentina. Buenos Aires: Ministerio de Agricultura, Ganadería, Pesca y Alimentación, 2013. 96 p.

ARGENTINA. (2014) Monitoreo de la superficie de bosque nativo de la República Argentina. Período 2011-2013. Regiones forestales Parque Chaqueño, Selva Tucumano Boliviana, Selva Misionera y Espinal. Buenos Aires: Secretaría de Ambiente y Desarrollo Sustentable de la Nación. 67 p.

ARGENTINA. (2015a) Estadísticas agrícolas, por cultivos, campañas, provincias y departamentos. Buenos Aires: Ministerio de Agricultura, Ganadería y Pesca, 2015a. Disponible en: http://old.siia.gov.ar/index.php/series-por-tema/ agricultura. Acceso en: 25 de marzo de 2015.

ARGENTINA. (2015b) Área con producción de soja. Campaña 2011-2012. Buenos Aires: Ministerio de Agricultura de la Nación. Disponible en: http://www.minagri.gob.ar/site/areas/tierras/02_datos_geoedaficos/10_Uso\%20del\%20 suelo/_archivos1/090000_Soja/090000_Soja.pdf?PHPSESSID=0f97506f00172fef5543365f68e289e9. Acceso en: 28 de octubre de 2015. 
ARGENTINA. (2015c) Exportaciones según complejos exportadores. Año 2014. Buenos Aires: Instituto Nacional de Estadística y Censos. Disponible en: http://www.indec.gov.ar/nivel4_default.asp?id_tema_1=3\&id_tema_2=2\&id_ tema_3=39. Acceso en: 16 oct. 2015.

ARGENTINA. (2015d) Monitoreo de la superficie de bosque nativo de la República Argentina. Período 2013-2014. Regiones forestales Parque Chaqueño, Yungas Selva Paranænse y Espinal. Buenos Aires: Secretaría de Ambiente y Desarrollo Sustentable de la Nación. 85 p.

ARGENTINA INDYMEDIA. (2011) Para el ministro, el glifosato es como 'agua con sal'. Disponible en: http://argentina. indymedia.org/news/2011/08/791009.php. Acceso en: 26 ag. 2015.

ÁVILA VÁZQUEZ, M.; RUDERMAN, L.; MATURANO, E.; MACLEAN, B.; AICHINO, L.; MARINO, D.; ANDRINOLO, D.; ETCHEGOYEN, A. (2013) Evaluación de la salud colectiva socio-ambiental de Monte Maíz. Córdoba: Red Universitaria de Ambiente y Salud. 27 p.

BECK, U. (1998) La sociedad del riesgo. Hacia una nueva modernidad. Barcelona: Paidós. 305 p.

BECK, U. (2001) La sociedad del riesgo global. Madrid: Siglo XXI. 291 p. WD10J

BELLISARIO, A. (2003) El nuevo imperialismo americano. Tiempo y Espacio, Chillán, a 3, n. 13, p. 53-59.

CARRASCO, A. (2011) Efecto del glifosato en el desarrollo embrionario de Xenopus laevis. Teratogénesis y glifosato. Disponible en: http://www.reduas.com.ar/glifosato-y-teratogenesis-malformaciones-congenitas-y-glifosato/. Acceso en: 10 sep. 2015.

COMPOSTO, C. (2012) Acumulación por despojo y neoextractivismo en América Latina. Una reflexión crítica acerca del Estado y los movimientos socio-ambientales en el nuevo siglo. Astrolabio, Buenos Aires, n. 8. p. 323-352.

DELGADO, O. (2008) La ruta de la soja en el Noroeste Argentino. In: RULLI, J. (coord.). Repúblicas unidas de la soja. Realidades sobre la producción de soja en América del Sur. Buenos Aires: GRR, p. 132-158.

ELEISEGUI, P. (2015) Argentina envenenada: proliferan el cáncer y las malformaciones por el uso de químicos para producir alimentos. Disponible en: http://www.iprofesional.com/notas/212108-Argentina-envenenada-proliferan-elcncer-y-las-malformaciones-por-el-uso-de-qumicos-para-producir-alimentos. Acceso en: 11 oct. 2015.

GALLO, G. (2010) Agroquímicos prohibidos o restringidos. Buenos Aires: Ministerio de Agricultura de la Nación. 17 p.

GARIBAY OROZCO, C. (2010) Paisajes mineros de acumulación por desposesión campesina en el México actual. In: DELGADO RAMOS, G. (coord.). Ecología política de la minería en América Latina. Aspectos socioeconómicos, legales y ambientales de la mega minería. México: Universidad Autónoma Nacional de México, p. 133-182.

GÓMEZ LENDE, S. (2015) Acumulación por desposesión y conflictos espaciales: La minería metalífera en la Argentina contemporánea. Saarbrücken: Editorial Académica Española. 117 p.

GÓMEZ LENDE, S; VELÁZQUEZ, G. Á. (2013) Orden global, reestructuración productiva y crisis ambiental: análisis de la relación entre deforestación, soja transgénica y silvicultura en la Argentina contemporánea. In: CACACE, G. P.; GÓMEZ, M. E.; MORINA, J. O.; SUEVO, M. E. (coord./comp.). Geografías regionales y extractivismos en la Argentina de los Bicentenarios. Luján: UNLu, p. 23-86.

GRR. (2009) Pueblos fumigados. Los efectos de los plaguicidas en las regiones sojeras. Buenos Aires: Grupo de Reflexión Rural, Editorial del Nuevo Extremo. 254 p.

HARVEY, D. (2004) El nuevo imperialismo. Madrid: Akal. 170 p.

HARVEY, D. (2006) El nuevo imperialismo. Entrevista. Disponible en: http://www.sinpermiso.info/textos/el-nuevoimperialismo-entrevista. Acceso en: 11 sept. 2015.

JOENSEN, L. (2008) Pueblos fumigados en Argentina. In: RULLI, J. (coord.). Repúblicas unidas de la soja. Realidades sobre la producción de soja en América del Sur. Buenos Aires: GRR, p. 160-190.

MACHADO ARAOZ, H. (2010) El agua vale más que el oro. Grito de resistencia decolonial contra los nuevos dispositivos expropiatorios. In: DELGADO RAMOS, G. (coord.). Ecología política de la minería en América Latina. Aspectos socioeconómicos, legales y ambientales de la mega minería. México: Universidad Autónoma Nacional de México, p. 59-96.

MERENSON, C. (2011) Estimación del pasivo ambiental del cultivo de soja en Argentina. Buenos Aires: Centro de Estudios e Investigación Social Nelson Mandela. 13 p.

MONTENEGRO, R. (2009) Informe sobre los efectos de los plaguicidas en la salud humana. Necesidad de prohibir el uso de plaguicidas agropecuarios en áreas urbanas y periurbanas. Disponible en: https://observatoriodelglifosato. wordpress.com/2009/08/03/informe-sobre-los-efectos-de-los-plaguicidas-en-la-salud-humana-y-el-ambiente/. Acceso en: 20 oct. 2015.

MORINA, J. O. (2010) Palabras preliminares. In: MORINA, J. O. (ed., dir. y comp.). Geografías de la agricultura industrial sojera en la Argentina. ¿Viaje de ida? Luján: UNLu, p. 5-10. 
MORINA, J. O.; CACACE, G. P. (2013) Capitalismo agrario y expansión sojera en la Argentina: ¿un extractivismo sin retorno? In: CACACE, G. P.; GÓMEZ, M. E.; MORINA, J. O.; SUEVO, M. E. (coord./comp.). Geografías regionales y extractivismos en la Argentina de los Bicentenarios. Luján: UNLu, p. 287-328.

PÁGINA 12. (2006) Malformaciones a todo campo". Diario Página 12. Disponible en: http://webs.chasque.net/ rapaluy1/ agrotoxicos/Prensa/malformaciones_campo.html. Acceso en: 18 sept. 2015.

PENGUE, W. (2005) Agricultura industrial y transnacionalización en América Latina. ¿La transgénesis de un continente? Buenos Aires: PNUMA. 221 p.

PENGUE, W. (2006) Agua virtual, agronegocio sojero y cuestiones económico-ambientales futuras. Realidad Económica, Buenos Aires, n. 223, p. 58-77.

PERALTA, L.; MAÑAS, F., GENTILE, N.; BOSCH, B.; MÉNDEZ, Á.; AIASSA, D. (2011) Evaluación del daño genético en pobladores de Marcos Juárez expuestos a plaguicidas: estudio de un caso en Córdoba, Argentina. Diálogos. Revista Científica de Psicología, Ciencias Sociales, Humanidades y Ciencias de la Salud, San Luis v. 2, n. 1, pp. 7-26.

PERELMUTER, T. (2011) Bienes comunes vs. mercancías: las semillas en disputa. Un análisis del rol de la propiedad intelectual en los actuales procesos de cercamientos. Sociedades rurales. Producción y medio ambiente, México, a. 11, v. 11, n. 22 , p. $53-86$.

PÉREZ, G. (2015) Agrotóxicos. Cuando el campo envenena. Disponible en: http://www.miradasalsur.com.ar/2015/10/26/ revista/agrotoxicos-cuando-el-campo-envenena/ . Acceso en: 6 nov. 2015.

PIERRI, J. (2006) El boom de la soja. Un retorno al pasado. Realidad Económica, Buenos Aires, n. 219, p. 53-65.

REDAF. (2013) Conflictos sobre tenencia de tierra y ambientales en la región del Chaco argentino $3^{\circ}$ informe. Reconquista: Red Agroforestal Chaco Argentina, Observatorio de Recursos Naturales, Tierras y Medioambiente. 100 p.

REDUAS. (2010) Informe $1^{\circ}$ Encuentro Nacional de Médicos de Pueblos Fumigados. Córdoba: Facultad de Ciencias Médicas, Universidad Nacional de Córdoba. 40 p.

REDUAS. (2013) El consumo de agrotóxicos em Argentina aumenta continuamente. Análisis de los datos del mercado de pesticidas en Argentina. Buenos Aires: Red Universitaria de Ambiente y Salud/Red de Médicos de Pueblos Fumigados. $6 \mathrm{p}$.

REDUAS. (2014) China comienza a cuestionar a transgénicos y glifosato. Buenos Aires: Red Universitaria de Ambiente y Salud/Red de Médicos de Pueblos Fumigados. Disponible en: http://www.reduas.com.ar/china-comienza-a-cuestionara-transgenicos-y-glifosato/. Acceso en: 20 oct. 2015.

SACHER, W. (2015) Megaminería y desposesión en el Sur: un análisis comparativo. Íconos. Revista de Ciencias Sociales, Quito, n. 51, p. 91-116.

SANTOS, M. (1996a) A natureza do espaço. Técnica e tempo, razão e emoção. São Paulo: Hucitec. 257 p.

SANTOS, M. (1996b) De la totalidad al lugar. Barcelona: Oikos-Tau. 124 p.

SANTOS, M.; SILVEIRA, M. L. (2001) O Brasil. Território e sociedade no início do século XXI. Rio de Janeiro-São Paulo: Record. $473 \mathrm{p}$.

SILVEIRA, M. L. (1999) Um país, uma região. Fim de século e modernidades na Argentina. São Paulo: LABOPLAN-USP. $488 \mathrm{p}$.

SILVEIRA, M. L. (2003) Argentina: território e globalização. São Paulo: Brasiliense. 100 p.

TETREAULT, D. (2013) Los mecanismos del imperialismo canadiense en el sector minero de América Latina. Estudios críticos del desarrollo, Zacatecas, v. 3, n. 4, p. 191-215.

TEUBAL, M.; PALMISSANO, T. (2013) Crisis alimentaria y crisis global: la Argentina de 2001/2002 y después. Realidad Económica, Buenos Aires, n. 279, p. 47-74. 